\title{
Functionalizable Oligoprolines as Molecular Scaffolds
}

\author{
Yvonne A. Nagel§, Michael Kuemin, and Helma Wennemers* \\ §SCS DSM Prize for best poster
}

\begin{abstract}
Azidoproline (Azp) containing oligoprolines are conformationally well-defined, helical molecular scaffolds that allow for facile functionalization. Within this article we describe the synthesis of Azp-containing oligoprolines and different strategies to introduce functional moieties. In addition, the influence of factors such as substituents at the $\gamma$-position of proline as well as functional groups at the termini on the conformational stability of the molecular scaffolds are briefly presented.
\end{abstract}

Keywords: Azidoproline · Functionalization · Molecular scaffolds · Oligoprolines · Peptides

\section{Introduction}

Functionalizable, conformationally welldefined helical structures have become important as molecular scaffolds for applications ranging from the development of cell-penetrating peptides, ${ }^{[1]}$ antibiotics, ${ }^{[2]}$ and inhibitors of protein-protein interactions $^{[3]}$ to the design of new materials. ${ }^{[4]}$ Oligoprolines are interesting in this respect since they adopt already at short chain lengths of six residues the conformationally well-defined polyproline II (PPII) helix in aqueous environments. ${ }^{[5-9]}$ This secondary structure is widespread in nature and a highly symmetrical helix where every third residue is stacked on top of each other with a pitch of $\sim 9.5 \AA .{ }^{[7,8]}$ A further attractive feature of oligoprolines is the possibility to switch between the PPII and another helical conformation, the polyproline I (PPI) helix, by changing the solvent. ${ }^{[7,9]}$ Oligoprolines adopt the left-handed PPII helix with all amide bonds in trans conforma- tions in aqueous solution, whereas a switch to the more compact right-handed PPI helix with all amide bonds in cis conformations occurs in more hydrophobic solvents like $n$-PrOH (Fig. 1a). ${ }^{[7-9]}$

This special feature of oligoprolines originates from the unique properties of proline (Pro) amongst the proteinogenic amino acids. The cyclic nature of Pro combined with the secondary amine leads to constrained dihedral angles and a tertiary amide in the peptidic backbone. Whereas trans amide bonds are energetically strongly favored within secondary amide bonds, the cis conformation is populated to a significant extent in the tertiary amide bonds of Xaa-Pro motives. ${ }^{[10]}$
Our group has introduced 4-azidoproline (Azp) containing oligoprolines as conformationally well-defined functionalizable molecular scaffolds. ${ }^{[1-14]}$ Incorporation of Azp residues into oligoprolines introduces sites for further functionalizations at defined positions. For example, oligoprolines with Azp residues in every third position provide for functionalizable sites in distances of $9.5 \AA$ (Fig. 1b). [11] Herein we describe the synthesis of Azp-containing oligoprolines and different strategies to functionalize them. In addition, the influence of factors that influence the conformational stability of the oligoproline-based scaffold are briefly discussed. ${ }^{[15,16]}$

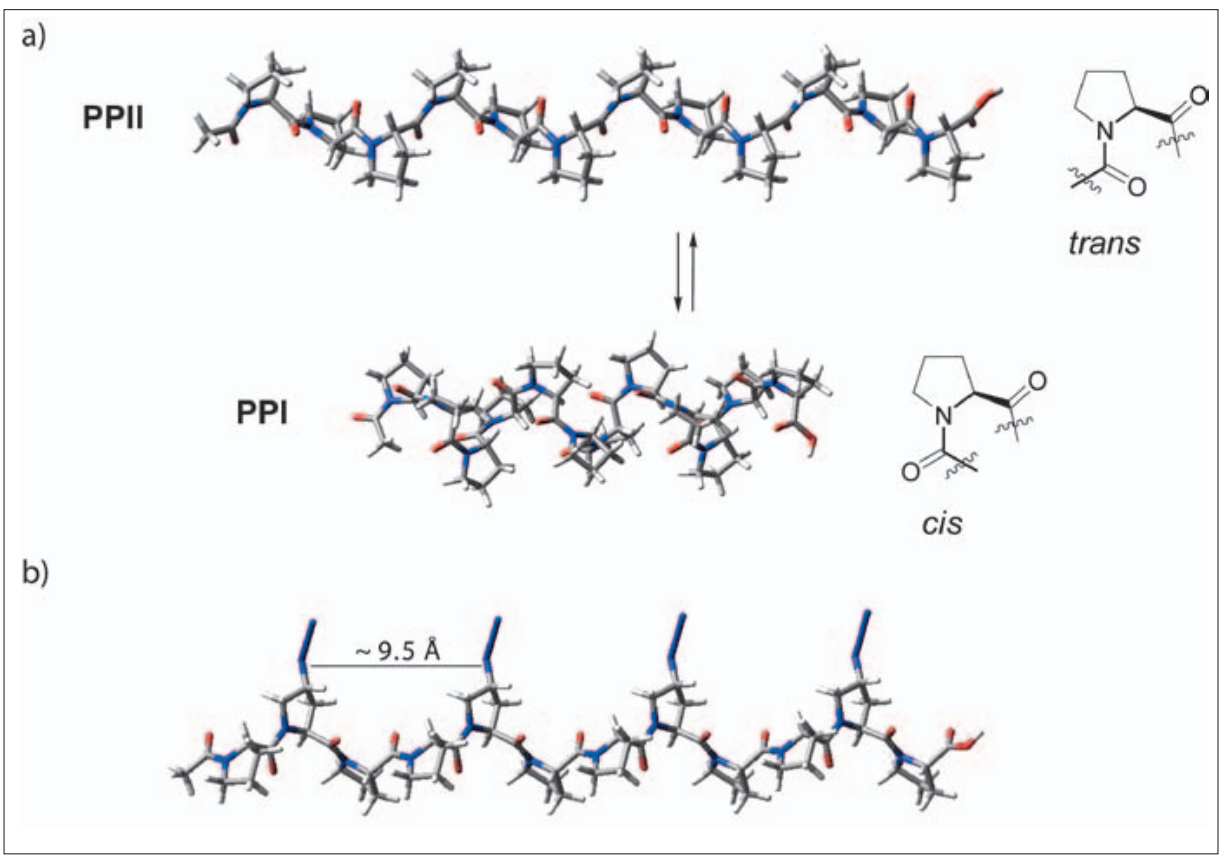

Fig. 1. a) Models of the PPII helix with all trans amide bonds (top) and the PPI helix with all cis amide bonds (bottom). b) Model of a PPII helix of an oligoproline with Azp residues at every third position. 


\section{Synthesis of Azp-containing Oligoprolines}

For the synthesis of Azp-containing oligoprolines we envisioned either successive coupling of Fmoc-Pro-OH and Fmoc(4S)Azp-OH (1S) or Fmoc-(4R)Azp-OH (1R) using standard solid phase peptide synthesis (SPPS) following the Fmoc/t $\mathrm{Bu}$ protocol or the coupling of dimeric or trimeric building blocks such as Fmoc-Pro(4S)Azp-Pro-OH (2S) or Fmoc-Pro- $(4 R)$ Azp-Pro-OH (2R). The latter approach should in particular be valuable for longer sequences to avoid deletion sequences that might render the purification of the desired oligoprolines difficult. The synthesis of Fmoc-(4S)Azp-OH (1S) and Fmoc- $(4 R)$ Azp-OH (1R) from commercially available $t$-butyloxycarbonyl (Boc) protected (4R)-hydroxyproline (Boc- $(4 R) \mathrm{Hyp}-\mathrm{OH}$, 3 ) proved straightforward (Scheme 1). ${ }^{[1]}$ Esterification of Boc- $(4 R) \mathrm{Hyp}-\mathrm{OH}(3)$ followed by activation of the hydroxy group as a mesylate and $\mathrm{S}_{\mathrm{N}} 2$ substitution with sodium azide yielded the azidoproline derivative Boc-(4S)Azp-OCH 3 (5S). Hydrolysis of the methyl ester, removal of the Boc protecting group and reprotection of the amine with Fmoc-Cl under Schotten-Baumann conditions provided the desired Fmoc-protected azidoproline building block Fmoc$(4 S) \mathrm{Azp}-\mathrm{OH}(\mathbf{1 S})$. To access the $(4 R)$ configured Azp-diastereoisomer (1R) the hydroxyproline derivative $\mathbf{4}$ was converted to a mesylate with inversion of the absolute configuration at C(4) by a Mitsunobu reaction with methanesulfonic acid. $\mathrm{S}_{\mathrm{N}} 2$ substitution with sodium azide again with inversion of the absolute configuration at $\mathrm{C}(4)$ yielded the $N$-Boc-(4R)-azidoproline methyl ester (Boc-(4R)Azp-OCH, $5 R$ ). Manipulations of the protecting groups of the amino acid as outlined for the diastereoisomer $\mathbf{1 S}$ yielded the Fmoc-protected building block Fmoc-(4R)Azp-OH (1R).

The syntheses of these Fmoc-protected azidoproline derivatives are easily accomplished on a multigram scale allowing the routine preparation of $10-100 \mathrm{~g}$ of both Fmoc- $(4 S)$ Azp-OH (1S) and Fmoc- $(4 R)$ Azp-OH (1R) in a regular academic laboratory.

Also the synthesis of the trimeric building blocks Fmoc-Pro-(4S)Azp-Pro$\mathrm{OH}(\mathbf{2 S})$ and Fmoc-Pro-(4R)Azp-Pro-OH (2R) that were envisioned for the synthesis of oligoprolines with Azp residues in every third position was straightforward. Both building blocks were synthesized as illustrated in Scheme 2 for the example of Fmoc-Pro-(4R)Azp-Pro-OH (2R). After removal of the Boc protecting group of Boc-(4R)Azp-OCH $\mathrm{OH}_{3}(\mathbf{5 R})$, the resulting amine was coupled with Boc-Pro-OH using $\quad N$-(3-dimethylaminopropyl)- $N^{\prime}$ ethylcarbodiimide hydrochloride (EDC)

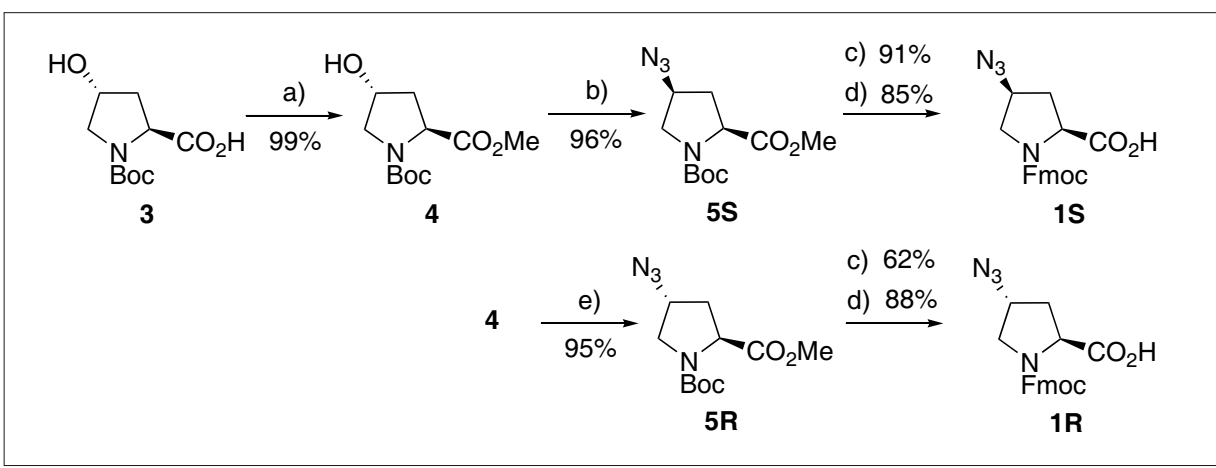

Scheme 1. Synthesis of Fmoc-(4S)Azp-OH (1S) and Fmoc-(4R)Azp-OH (1R): a) i) $\mathrm{Cs}_{2} \mathrm{CO}_{3}(0.55$ equiv.), $\mathrm{MeOH}, \mathrm{H}_{2} \mathrm{O}, \mathrm{RT}$; ii) Mel (2 equiv.), DMF, RT; b) i) $\mathrm{CH}_{3} \mathrm{SO}_{2} \mathrm{Cl}$ (1.5 equiv.), $\mathrm{NEt}_{3}$ (3 equiv.), $\mathrm{CH}_{2} \mathrm{Cl}_{2}, 0^{\circ} \mathrm{C}$; ii) $\mathrm{NaN}_{3}$ (5 equiv.), DMF, $80^{\circ} \mathrm{C}$; c) i) $\mathrm{NaOH}$ (2 equiv.), $\mathrm{H}_{2} \mathrm{O}, \mathrm{MeOH}, \mathrm{THF}, \mathrm{RT}$; ii) $4 \mathrm{M}$ $\mathrm{HCl}$ in dioxane (20 equiv.), $\mathrm{RT}$; d) $\mathrm{Fmoc}-\mathrm{Cl}$ (1.2 equiv.), $\mathrm{NaHCO}_{3}$ (2.5 equiv.), $\mathrm{H}_{2} \mathrm{O}$, dioxane, $\mathrm{RT}$; e) i) $\mathrm{CH}_{3} \mathrm{SO}_{3} \mathrm{H}$ (1.2 equiv.), $\mathrm{PPh}_{3}$ (1.8 equiv.), DIAD (2 equiv.), $\mathrm{NEt}_{3}\left(0.4\right.$ equiv.), toluene, $0{ }^{\circ} \mathrm{C}-70{ }^{\circ} \mathrm{C}$; ii) $\mathrm{NaN}_{3}$ (5 equiv.), DMF, $80^{\circ} \mathrm{C}$.

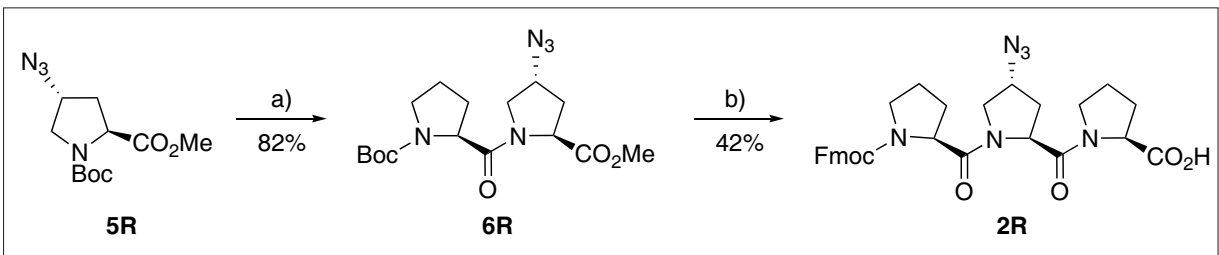

Scheme 2. Synthesis of the tripeptidic building block Fmoc-Pro-(4R)Azp-Pro-OH (2R): a) i) 4M $\mathrm{HCl}$ in dioxane (20 equiv.), RT; ii) Boc-Pro-OH (1.2 equiv.), EDC (1.5 equiv.), $\operatorname{Pr}_{2} \mathrm{NEt}$ (1.2 equiv.), $\mathrm{CH}_{2} \mathrm{Cl}_{2}, \mathrm{RT}$; b) i) $\mathrm{NaOH}$ (1.2 eq), $\mathrm{H}_{2} \mathrm{O}, \mathrm{THF}, \mathrm{MeOH}, \mathrm{RT}$; ii) $\mathrm{H}-\mathrm{Pro}^{-} \mathrm{OCH}_{3}$ (1.2 equiv.), EDC (1.5 equiv.), $i \operatorname{Pr}_{2} \mathrm{NEt}$ (1.2 equiv.), $\mathrm{CH}_{2} \mathrm{Cl}_{2}, \mathrm{RT}$; iii) repeat steps bi) and ai); iv) $\mathrm{Fmoc}-\mathrm{Cl}$ (1.2 equiv.), $\mathrm{NaHCO}_{3}$ (2.5 equiv.), $\mathrm{H}_{2} \mathrm{O}$, dioxane, $\mathrm{RT}$.

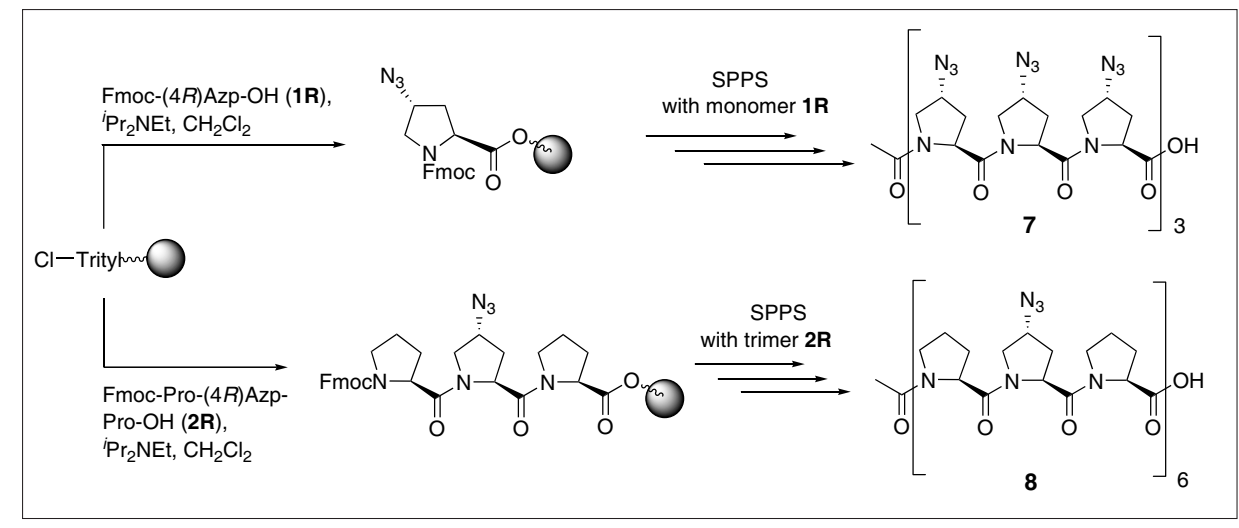

Scheme 3. Synthesis of Azp-containing oligoprolines 7 (top) and $\mathbf{8}$ (bottom) by monomer couplings and trimer couplings respectively on solid phase.

to the dipeptide Boc-Pro-(4R)Azp-OCH (6R). Hydrolysis of the methyl ester of $\mathbf{6 R}$ and coupling with H-Pro-OMe yielded then the trimer Boc-Pro- $(4 R)$ Azp-Pro- $\mathrm{OCH}_{3}$. Removal of the protecting groups followed by Fmoc-protection of the resulting amine provided then the desired trimer building block Fmoc-Pro(4R)Azp-Pro-OH $(\mathbf{2} \mathbf{R})$ readily usable in standard SPPS.

For the synthesis of Azp-containing oligoprolines using the monomeric building blocks Fmoc-(4S)Azp-OH (1S) or Fmoc-(4R)Azp-OH (1R) on solid support, 2-(6-chloro-1H-benzotriazole-1-yl)1,1,3,3-tetramethylaminium hexafluoro- phosphate (HCTU) or 2-(7-aza-1H-benzotriazole-1-yl)-1,1,3,3-tetramethyluronium hexafluorophosphate (HATU) and Hünig's base proved valuable as coupling reagents. Oligomers up to a length of nine residues were readily prepared by alternating peptide coupling with Fmoc-deprotection (20\% piperidine in DMF) steps using either Rink amide or chlorotrityl linkers to polystyrene or TentaGel solid supports. Using this standard SPPS protocol, oligoprolines such as the 9-mer 7, were obtained after acid-induced cleavage from the solid supports in purities that allowed for a facile further purification by preparative HPLC (Scheme 3). [11,13] 


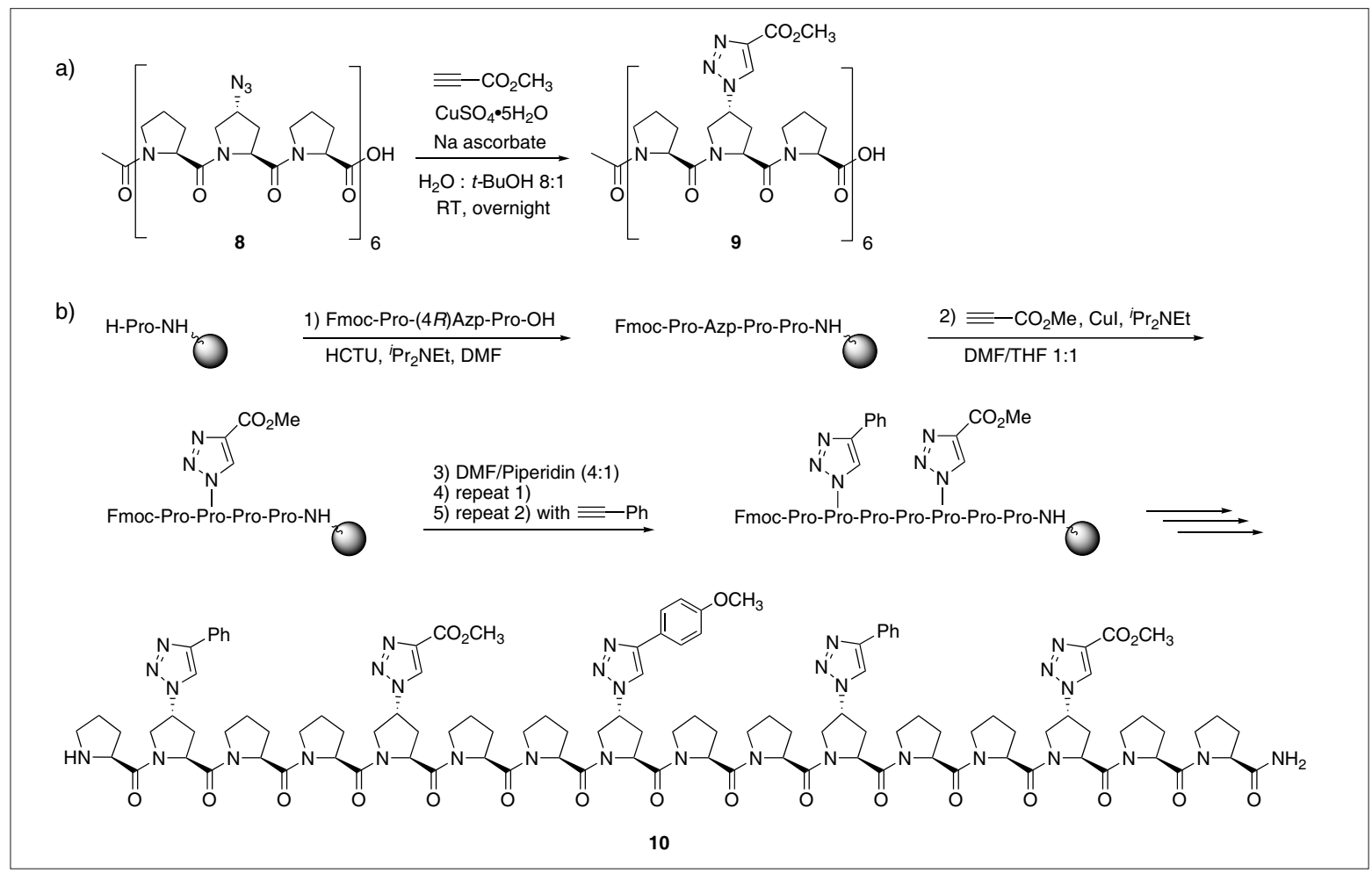

Scheme 4. a)

Functionalization

of Azp-containing

peptide 8 to

hexatriazole 9 by

'click chemistry'

in solution phase.

b) Synthesis of

the differentially

functionalized

oligoproline 10 by

sequential peptide

coupling and 'click

chemistry' steps on

solid phase.

For the synthesis of longer oligoprolines, such as the 18 -mer $\mathbf{8}$, the trimeric building block Fmoc-Pro-(4R)Azp-Pro$\mathrm{OH}(\mathbf{2 R})$ was coupled following an identical methodology using HCTU/Hünig's base as the coupling reagent. ${ }^{[11]}$

\section{Functionalizability of Azp-containing Oligoprolines}

Two strategies were envisioned for the functionalization of Azp-containing oligoprolines: a) reaction of the azides with alkynes using Huisgen's 1,3-dipolar cycloaddition ('click chemistry'). ${ }^{[17,18]}$ and b) reduction of the azides to amines and further reaction with carboxylic acid derivatives.

\subsection{Click Chemistry}

To evaluate the click-chemistry approach, the 18-mer 8 with six Azp residues was reacted under typical 'click chemistry' conditions using methyl propiolate, $\mathrm{CuSO}_{4} \cdot 5 \mathrm{H}_{2} \mathrm{O}$ and sodium ascorbate in a mixture of water and $t$-BuOH (Scheme 4a). ${ }^{[11]}$ The desired hexatriazole 9 was obtained in a yield of $40 \%$ after extraction and precipitation.

Whereas these click-reactions were performed in solution phase, functionalization is also readily feasible with the Azp-containing oligoproline still bound to a solid support. ${ }^{[11,12]}$ This strategy has the additional benefit that it allows for a differential functionalization of oligoprolines with different moieties by alternating peptide coupling and 'click chemistry' steps (Scheme 4b). ${ }^{[11,12]}$

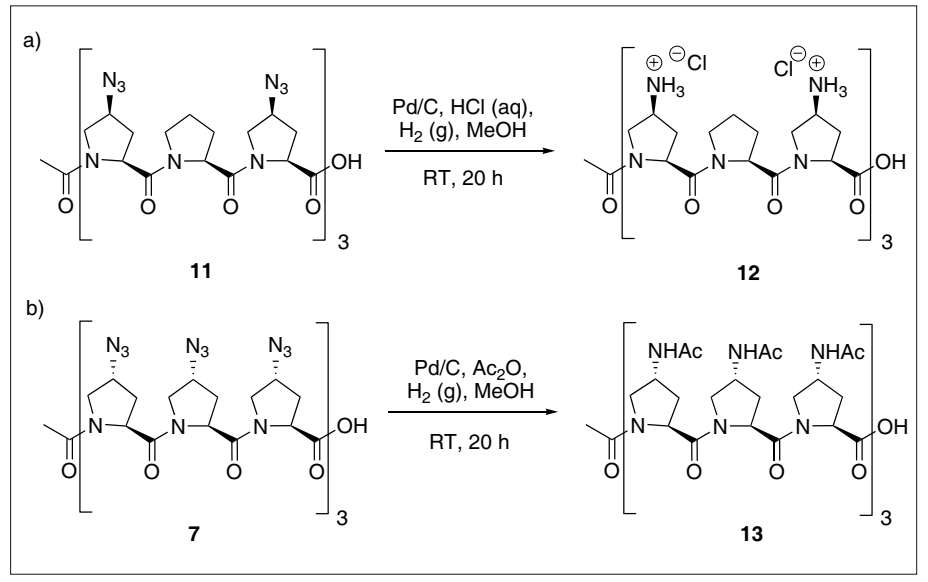

Scheme 5.

Functionalization of Azp-containing oligoprolines by a) reduction and $\mathrm{b}$ ) in situ reduction and acylation.

\subsection{Reduction and Amidation}

Also the reduction of the azido groups within Azp-containing oligoprolines proved straightforward. For example, the six azido groups within the 9-mer $\mathbf{1 1}$ were readily reduced to the hexaamine using $\mathrm{Pd}$ on activated carbon in a hydrogen atmosphere under acidic conditions (Scheme 5a). ${ }^{[13]}$ The resulting oligoprolines with six positively charged ammonium groups is not only interesting for the further functionalization of the molecular scaffold but might be interesting for its cell-penetrating properties which are currently under investigation. Reaction of the hexaamine 12 with activated carboxylic acids proceeded well, but also a one-pot reduction and acetylation of the azidoproline 9-mer 7 to the acetamido-containing oligoproline 13 worked well (Scheme 5b).

\section{Factors Influencing the Conformational Stability of the PPII Helix}

For applications of oligoprolines as molecular scaffolds a basic understanding of the factors that influence the structural stability of the PPII helix is important. We therefore probed the effect of functional groups derived from the azide in the $\gamma$-position $(\mathrm{C}(4))$ of proline and the effects of charged versus uncharged functional groups at the $\mathrm{N}$ - and $\mathrm{C}$-termini on the conformational properties of oligoprolines. ${ }^{[11-13,15,16]}$ Using the solvent-induced conformational switch of oligoprolines from the PPII to the PPI helix as a monitoring tool, the relative stability of PPII helices derived from several oligoprolines were evaluated. The studies revealed that a positive charge at the $\mathrm{N}$-terminus and a negative charge at the $\mathrm{C}$-terminus 
destabilize the PPII helix whereas capped (uncharged) termini favor the PPII helix relative to the PPI helix. ${ }^{[15]}$ The effect of functional groups in the $\gamma$-position of proline residues depends also on the absolute configuration at this chiral center. (4R)Configured proline derivatives with electron-withdrawing groups such as azides at $\mathrm{C}(4)$ stabilize the PPII helix relative to the PPI helix. ${ }^{[11]}$ Likewise (4S)-configured proline derivatives with hydrogen-bond donating groups such as ammonium ions at $\mathrm{C}(4)$ also stabilize the PPII helix relative to the PPI helix. ${ }^{[13]}$ These stabilizing and destabilizing effects correlate well with the influence of the substituent and the absolute configuration at $\mathrm{C}(4)$ on the cis:trans amide conformer equilibrium. ${ }^{[13,14]}$ They can be easily monitored and analyzed in simpler model compounds such as the respective acetylated methyl esters of the type Ac-Xaa-OCH${ }_{3} \cdot{ }^{[11,13,14]}$

\section{Conclusions}

Azidoproline-containing oligoprolines are attractive molecular scaffolds since they allow not only facile functionalization but adopt conformationally welldefined helical conformations already at short chain lengths ( $\geq 6$ residues). These features render Azp-containing oligoprolines intriguing for manifold different applications. Our basic conformational studies demonstrated that the functional groups at the $\mathrm{N}$ - and $\mathrm{C}$-termini as well as the absolute configuration of $\mathrm{C}(4)$ have to be selected carefully depending on the application. We are currently investigating the utility of appropriately functionalized oligoprolines as cell-penetrating peptides, for tumor targeting, and for the development of semiconducting materials. In addition, the versatility of Azp residues is used for the development of functionalizable collagen model peptides. ${ }^{[19]}$

Received: February 28, 2011

[1] For examples see: a) J. Iriondo-Alberdi, K. Laxmi-Reddy, B. Bouguerne, C. Staedel, I. Huc, ChemBioChem 2010, 11, 1679; b) I. Geisler, J. Chmielewski, Chem. Biol. Drug Des. 2009, 73, 39; c) B. A. Smith, D. S. Daniels, A. E. Coplin, G. E. Jordan, L. M. McGregor, A. Schepartz, J. Am. Chem. Soc. 2008, 130, 2948; d) S. Pujals, E. Giralt, Adv. Drug Del. Rev. 2008, 60, 473; e) J. Farrera-Sinfreu, E. Giralt, S. Castel, F. Albericio, M. Royo, J. Am. Chem. Soc. 2005, 127, 9459.

[2] For examples see: a) M. A. Schmitt, B. Weisblum, S. H. Gellman, J. Am. Chem. Soc. 2004, 126, 6848; b) D. Liu, W. F. DeGrado, $J$. Am. Chem. Soc. 2001, 123, 7553.

[3] For examples see: a) K. M. Bonger, V. V. Kapoerchan, G. M. Grotenbreg, C. J. v. Koppen, C. M. Timmers, G. A. v. d. Marel, H. S. Overkleeft, Org. Biomol. Chem. 2010, 8, 1881; b) S.-G. Lee, S. Hershberger, J. Chmielewski, Curr. Top. Med. Chem. 2007, 7, 928; c) O. M. Stephens, S. Kim, B. D. Welch, M. E. Hodson, M. S. Kay, A. Schepartz, J. Am. Chem. Soc. 2001, 123, 7553 .

[4] For examples see: a) L. E. Russel, J. A. Fallas, J. D. Hartgerink, J. Am. Chem. Soc. 2010 , 132, 3242; b) M. M. Pires, D. E. Przybyla, J. Chmielewski, Angew. Chem. Int. Ed. 2009, 48, 7813; c) F. W. Kotch, R. T. Raines, Proc. Natl. Acad. Sci. USA 2006, 103, 3028; d) U. Kusebauch, S. A. Cadamuro, H.-J. Musiol, M. O. Lenz, J. Wachtveitl, L. Moroder, C. Renner, Angew. Chem. Int. Ed. 2006, 45, 7015.

[5] For examples of the use of oligoprolines as 'molecular rulers', see a) B. Schuler, E. A.
Lipman, P. J. Steinbach, M. Kumke, W. A. Eaton, Proc. Natl. Acad. Sci. USA 2005, 102, 2754; b) a) M. Cordes, A. Kottgen, C. Jasper, O. Jacques, H. Boudebous, B. Giese, Angew. Chem. Int. Ed. 2008, 47, 3461.

[6] M. Rothe, H. Rott, J. Mazanek, J. Pept., Proc Eur. Pept. Symp., 14 $4^{\text {th }} \mathbf{1 9 7 6}, 309$.

[7] F. Rabanal, M. D. Ludevid, M. Pons, E. Giralt, Biopolymers 1993, 33, 1019.

[8] A. Rath, A. R. Davidson, C. M. Deber, Biopolymers 2005, 80, 179.

[9] S. Kakinoki, Y. Hirano, M. Oka, Polymer Bull. 2005, 53, 109

[10] G. Fischer, Chem. Soc. Rev. 2000, 29, 119.

[11] M. Kümin, L.-S. Sonntag, H. Wennemers, J. Am. Chem. Soc. 2007, 129, 566.

[12] R. S. Erdmann, M. Kümin, H. Wennemers, Chimia 2009, 63, 197.

[13] M. Kuemin, Y. A. Nagel, S. Schweizer, F W. Monnard, C. Ochsenfeld, H. Wennemers, Angew. Chem. Int. Ed. 2010, 49, 6324.

[14] L.-S. Sonntag, S. Schweizer, C. Ochsenfeld, H. Wennemers, J. Am. Chem. Soc. 2006, 128 , 14697.

[15] M. Kuemin, S. Schweizer, C. Ochsenfeld, H. Wennemers, J. Am. Chem. Soc. 2009, 131, 15474 .

[16] M. Kuemin, J. Engel, H. Wennemers, J. Pept. Sci. 2010, 16, 596.

[17] a) V. V. Rostovtsev, L. G. Green, L. G.; V. V. Fokin, K. B. Sharpless, Angew. Chem. Int. Ed. 2002, 41, 2596; b) C. W. Tornøe, C. Christensen, M. Meldal, M. J. Org. Chem. 2002, 67, 3057.

[18] J. M. Holub, H. Jang, K. Kirshenbaum, Org. Biomol. Chem. 2006, 4, 1497.

[19] R. S. Erdmann, H. Wennemers, J. Am. Chem. Soc. 2010, 132, 13957. 